\title{
Atrial Fibrillation (AF) and Complete Right Bundle Branch Block (RBBB) Are Independently Associated with Increased Hemoglobin Levels in Apparently Healthy Subjects
}

\author{
Eiji Oda ${ }^{1}$, Masato Oda ${ }^{2}$ and Yoshifusa Aizawa ${ }^{3}$
}

\begin{abstract}
Objective The associations between atrial fibrillation (AF) or complete right bundle branch block (RBBB) and other laboratory tests have not been examined sufficiently in healthy populations.

Methods These associations were examined with multivariable logistic regression analyses using data from 6,381 apparently healthy subjects including 46 subjects with AF and 100 subjects with RBBB.

Results The mean age, body mass index (BMI), hemoglobin, the prevalence of male sex and a history of coronary heart disease (CHD) were significantly higher in subjects with AF or RBBB than without. The odds ratio (OR) (95\% confidence interval (CI)) of AF was $1.62(1.28-2.05) \mathrm{p}<0.0001$ for each $1 \mathrm{~g} / \mathrm{dL}$ increment of hemoglobin and $1.07(0.36-3.21) \mathrm{p}=0.90$ and $4.32(1.29-14.43) \mathrm{p}=0.017$, respectively for the second and the third tertiles of hemoglobin compared with the first tertile after adjusting for sex, age, BMI, CHD, and other confounding covariates. The OR $(95 \% \mathrm{CI})$ of RBBB was $1.53(1.32-1.77) \mathrm{p}<0.0001$ for each $1 \mathrm{~g} / \mathrm{dL}$ increment of hemoglobin and $2.53(1.06-6.00) \mathrm{p}=0.036,3.10(1.12-8.61) \mathrm{p}=0.030$, and $4.03(0.91-17.82) \mathrm{p}=0.066$, respectively, for the second, third, and fourth quartiles of hemoglobin compared with the first quartile after adjusting for sex, age, BMI, CHD, and other confounding covariates.

Conclusion An increased blood levels of hemoglobin was independently associated with AF and RBBB after adjusting for sex, age, BMI, CHD, and other confounding covariates in apparently healthy subjects.
\end{abstract}

Key words: atrial fibrillation, right bundle branch block, hemoglobin, erythropoietin

(Intern Med 52: 37-43, 2013)

(DOI: 10.2169/internalmedicine.52.8881)

\section{Introduction}

Atrial fibrillation (AF) is the most common arrhythmia encountered in clinical practice, accounting for approximately one third of all hospitalizations for cardiac rhythm disturbances (1). The prevalence of AF increases with age, reaching as high as $9 \%$ in octogenarians in the US $(2,3)$. $\mathrm{AF}$ is associated with an increased risk of stroke, heart failure, and all-cause mortality, especially in females (1). The mortality rate of patients with $\mathrm{AF}$ is higher than that of patients in normal sinus rhythm and is linked to the severity of underlying heart disease $(2,3)$. The prevalence of complete right bundle branch block (RBBB) also increases with age (4). Although RBBB can indicate the presence of an underlying heart or lung disease, if a thorough evaluation reveals no such medical condition, then the RBBB is likely benign (5). However, some studies have indicated that, compared with control subjects, patients with RBBB had more sudden death and deaths from unknown causes (6). The right bundle branch is susceptible to damage and stretching whenever the right ventricle is placed under stress of any kind, including that induced by coronary heart disease (CHD), myocarditis, atrial septal defects, ventricular septal defects, valvular heart disease, and any lung disease that causes pulmonary hypertension.

In this study, we examined the associations between $\mathrm{AF}$ and RBBB with other laboratory test parameters in 6,381

${ }^{1}$ Medical Check-up Center, Tachikawa Medical Center, Japan, ${ }^{2}$ Division of Cardiology, Niigata Graduate School of Medical and Dental Sciences, Japan and ${ }^{3}$ Department of Research and Development, Tachikawa Medical Center, Japan

Received for publication August 29, 2012; Accepted for publication September 30, 2012

Correspondence to Dr. Eiji Oda, ijie@venus.sannet.ne.jp 
apparently healthy males and females because these associations have not been examined sufficiently in previous studies.

\section{Materials and Methods}

\section{Subjects}

Between April 2008 and March 2009, 7,568 male and female subjects underwent electrocardiography (ECG) at our Medical Check-up Center for general health screening. Of them, 6,381 subjects who filled out a questionnaire including questions about their history of stroke and CHD, smoking status, and antihypertensive, antidiabetic, and antihypercholesterolemic medications and whose hemoglobin levels were measured were enrolled in the present study. This study was approved by the ethics committee of the Tachikawa Medical Center.

\section{Measurements}

AF was diagnosed by the replacement of consistent $\mathrm{P}$ waves with rapid oscillations or fibrillatory waves that varied in amplitude, shape, and timing, which were associated with an irregular, frequently rapid ventricular response (7), and RBBB was diagnosed when the QRS duration was 120 msec or longer in any two standard leads, the $\mathrm{S}$ duration was $40 \mathrm{msec}$ or longer in Lead I, and R' or qR was present in the $\mathrm{V}_{1}$ or $\mathrm{V}_{2}$ lead (8).

After an overnight fast, blood samples were obtained to measure the blood levels of routinely evaluated laboratory values: plasma glucose, triglycerides, high-density lipoprotein (HDL) cholesterol, low-density lipoprotein (LDL) cholesterol, hemoglobin $(\mathrm{Hb}) \mathrm{A} 1 \mathrm{c}$, blood cell counts, and liver and kidney function tests. The simple qualitative urinalyses were performed with test papers. The chemical measurements were all performed at BML Nagaoka (Nagaoka, Japan) using routine laboratory methods, and the LDL cholesterol was measured with a direct surfactant method using Choletest-LDL (Sekisui Medical Inc., Tokyo, Japan). In 311 subjects whose LDL cholesterol was not directly measured and whose triglycerides were lower than $400 \mathrm{mg} / \mathrm{dL}$, the LDL cholesterol was calculated using the Friedewald equation (9). The estimated glomerular filtration rate (GFR) was calculated as the estimated GFR $\left(\mathrm{mL} / \mathrm{min} / 1.73 \mathrm{~m}^{2}\right)=194 \times$ creatinine $e^{-1.094} \times$ age $^{-0.287}$ in males, and $194 \times$ creatinine $e^{-1.094} \times$ age $^{-0.287} \times 0.739$ in females according to the recommendation from the Japanese Society of Nephrology (10). Respiratory function tests including the percent vital capacity (\%VC) and forced expiratory volume in 1 second (FEV1) divided by the forced vital capacity (FVC) (FEV1/FVC), were measured with Autospirometer System 7 (Minato Medical Science, Osaka, Japan). An average systolic blood pressure (SBP) and diastolic blood pressure (DBP) was calculated from two measurements taken with the subjects in a sitting position after a $5 \mathrm{~min}$ rest period. The body weight was measured with the subjects wearing light clothes provided by our center and the weight of the clothing was subtracted from the measured body weight. The body mass index (BMI) was calculated as the weight in kilograms divided by the square of the height in meters.

\section{Statistical analysis}

The non-adjusted background and laboratory data were compared between subjects with and without AF or RBBB. A stepwise multivariable logistic regression was performed using the AF or RBBB as a dependent variable and the sex, age, BMI, SBP, HDL cholesterol, LDL cholesterol, fasting glucose, HbA1c, leukocyte count, hemoglobin, platelet count, liver function test results, proteinuria, estimated GFR, $\%$ VC, FEV1/FVC, smoking status, antihypertensive medication, antidiabetic medication, antihypercholesterolemic medication, history of stroke, and history of CHD as covariates in 3,996 subjects who had all the above data including 34 subject with AF and 69 subjects with RBBB. About $40 \%$ of the subjects lacked some laboratory data included in the above analysis. Therefore, another stepwise multivariable logistic regression was performed using $\mathrm{AF}$ or RBBB as a dependent variable and the sex, age, BMI, SBP, hemoglobin, smoking status, antihypertensive medication, antidiabetic medication, antihypercholesterolemic medication, history of stroke, and history of CHD as covariates in 6,379 subjects who had all the above data including 46 subjects with AF and 100 subjects with RBBB. An exclusion criterion of $\mathrm{p}>$ 0.1 was used in the stepwise regressions. The hemoglobin levels were divided in tertiles and quartiles. The odds ratios (ORs) of AF for the second and the third tertiles of hemoglobin compared with the first tertile and the ORs of RBBB for the second, third, and the fourth quartiles of hemoglobin compared with the first quartile were calculated after adjusting for sex, age, smoking status, the three types of medications, and histories of stroke and CHD. The statistical analyses were performed using the Dr SPSS-2 software program (SPSS Japan Inc., Tokyo, Japan). Means were compared with two-sided t-tests, ratios were compared with chisquared tests. Values of $\mathrm{p}<0.05$ were considered to be statistically significant.

\section{Results}

The means of the laboratory data and the prevalence of male sex, current smoking, a history of CHD or stroke, use of antihypertensive medication, antihypercholesterolemic medication, and antidiabetic medication stratified by AF are presented in Table 1. Among the 6,381 subjects evaluated, 46 had AF. Some subjects lacked some laboratory data. The mean age, BMI, triglycerides, hemoglobin, and aspartate aminotransferase level, and the prevalence of male sex, a history of stroke, history of CHD, and use of antihypertensive medication were significantly higher in subjects with AF than in those without. The mean HDL cholesterol, alanine aminotransferase, platelet count, \%VC, and FEV1/ FVC were significantly lower in subjects with $\mathrm{AF}$ than those 
Table 1. Univariate Comparisons of Background and Laboratory Data between Subjects with and without Atrial Fibrillation (AF)

\begin{tabular}{|c|c|c|c|c|c|}
\hline & \multicolumn{2}{|r|}{ with AF } & \multicolumn{2}{|r|}{ without AF } & \multirow[b]{2}{*}{$\mathrm{p}$} \\
\hline & $\mathrm{n}$ & mean $(\mathrm{SD})$ or $\%$ & $\mathrm{n}$ & mean (SD) or \% & \\
\hline male sex $(\%)$ & 46 & 87.0 & 6,347 & 57.1 & $<0.0001$ \\
\hline age (years) & 46 & $62.1(10.7)$ & 6,347 & $50.3(10.3)$ & $<0.0001$ \\
\hline current smoking (\%) & 46 & 19.6 & 6,347 & 26.3 & 0.30 \\
\hline antihypertensives (\%) & 46 & 37.0 & 6,345 & 15.1 & $<0.0001$ \\
\hline antidiabetics $(\%)$ & 46 & 6.5 & 6,347 & 2.9 & 0.15 \\
\hline antihypercholesterolemics (\%) & 46 & 10.9 & 6,347 & 9.0 & 0.66 \\
\hline stroke $(\%)$ & 46 & 6.5 & 6,347 & 1.4 & 0.0043 \\
\hline coronary heart disease $(\%)$ & 46 & 37.0 & 6,347 & 2.7 & $<0.0001$ \\
\hline body mass index $\left(\mathrm{kg} / \mathrm{m}^{2}\right)$ & 46 & $24.2(3.5)$ & 6,347 & $22.6(3.3)$ & 0.0012 \\
\hline systolic blood pressure (mmHg) & 46 & $123(18)$ & 6,347 & $119(18)$ & 0.17 \\
\hline diastolic blood pressure $(\mathrm{mmHg})$ & 46 & $75(12)$ & 6,347 & $75(11)$ & 0.93 \\
\hline LDL cholesterol (mg/dL) & 46 & $113(26)$ & 6,347 & $121(30)$ & 0.069 \\
\hline HDL cholesterol (mg/dL) & 46 & $56.8(15.8)$ & 6,347 & $61.9(15.6)$ & 0.025 \\
\hline triglycerides (mg/dL) & 46 & $133(105)$ & 6,347 & $106(78)$ & 0.019 \\
\hline fasting glucose $(\mathrm{mg} / \mathrm{dL})$ & 46 & $97(15)$ & 6,318 & $94(17)$ & 0.21 \\
\hline hemoglobin A1c (\%) & 39 & $5.2(0.4)$ & 4,312 & $5.1(0.5)$ & 0.25 \\
\hline leucocyte count $\left(/ \mathrm{L}^{-6}\right)$ & 41 & $5,408(1,526)$ & 6,077 & $5,386(1,561)$ & 0.93 \\
\hline hemoglobin $(\mathrm{g} / \mathrm{dL})$ & 46 & $14.9(1.6)$ & 6,335 & $14.0(1.6)$ & 0.0003 \\
\hline platelet count $\left(/ \mathrm{L}^{-10}\right)$ & 38 & $21.3(6.1)$ & 4,551 & $24.1(5.3)$ & 0.0010 \\
\hline aspartate aminotransferase (U/L) & 46 & $28.8(12.8)$ & 6,347 & $22.9(13.2)$ & 0.0023 \\
\hline alanine aminotransferase (U/L) & 46 & $22.3(18.5)$ & 6,347 & $23.2(16.4)$ & 0.038 \\
\hline proteinuria $(\%)$ & 46 & 15.2 & 6,346 & 4.0 & 0.0001 \\
\hline estimated GFR $\left(\mathrm{mL} / \mathrm{min} / 1.73 \mathrm{~m}^{2}\right)$ & 34 & $75.4(17.7)$ & 3,998 & $78.6(13.2)$ & 0.16 \\
\hline vital capacity $(\%)$ & 35 & $91.4(12.4)$ & 4,367 & $96.4(11.5)$ & 0.0099 \\
\hline FEV1/FVC (\%) & 35 & $77.7(7.6)$ & 4,368 & $81.1(6.1)$ & 0.0014 \\
\hline
\end{tabular}

GFR: glomerular filtration rate, FEV1: forced expiratory volume in $1 \mathrm{sec}, \mathrm{FVC}$ : forced vital capacity

Table 2. Univariate Comparisons of Background and Laboratory Data between Subjects with and without Right Bundle Branch Block (RBBB)

\begin{tabular}{|c|c|c|c|c|c|}
\hline & \multicolumn{2}{|c|}{ with RBBB } & \multicolumn{2}{|c|}{ without RBBB } & \multirow[b]{2}{*}{$\mathrm{p}$} \\
\hline & $\mathrm{n}$ & mean (SD) or \% & $\mathrm{n}$ & mean $(\mathrm{SD})$ or $\%$ & \\
\hline male sex $(\%)$ & 100 & 79.0 & 6,281 & 57.0 & $<0.0001$ \\
\hline age (years) & 100 & $55.1(11.0)$ & 6,281 & $50.3(10.3)$ & $<0.0001$ \\
\hline current smoking (\%) & 100 & 32.0 & 6,281 & 26.2 & 0.19 \\
\hline antihypertensives (\%) & 100 & 20.0 & 6,279 & 15.2 & 0.19 \\
\hline antidiabetics $(\%)$ & 100 & 8.0 & 6,281 & 2.9 & 0.0026 \\
\hline antihypercholesterolemics (\%) & 100 & 17.0 & 6,281 & 8.9 & 0.0049 \\
\hline stroke $(\%)$ & 100 & 2.0 & 6,281 & 1.5 & 0.66 \\
\hline coronary heart disease $(\%)$ & 100 & 10.0 & 6,281 & 2.8 & $<0.0001$ \\
\hline body mass index $\left(\mathrm{kg} / \mathrm{m}^{2}\right)$ & 100 & $23.3(3.5)$ & 6,281 & $22.6(3.3)$ & 0.034 \\
\hline systolic blood pressure $(\mathrm{mmHg})$ & 100 & $124(20)$ & 6,281 & $119(18)$ & 0.016 \\
\hline diastolic blood pressure $(\mathrm{mmHg})$ & 100 & $77(13)$ & 6,281 & $75(11)$ & 0.028 \\
\hline LDL cholesterol (mg/dL) & 100 & $117(26)$ & 6,281 & $121(30)$ & 0.17 \\
\hline HDL cholesterol (mg/dL) & 100 & $59.7(18.4)$ & 6,281 & $62.0(15.6)$ & 0.15 \\
\hline triglycerides $(\mathrm{mg} / \mathrm{dL})$ & 100 & $112(67)$ & 6,281 & $106(78)$ & 0.52 \\
\hline fasting glucose $(\mathrm{mg} / \mathrm{dL})$ & 99 & $99(18)$ & 6,255 & $94(17)$ & 0.0051 \\
\hline hemoglobin A1c (\%) & 75 & $5.6(0.6)$ & 4,274 & $5.5(0.5)$ & 0.014 \\
\hline leucocyte count $\left(/ \mathrm{L}^{-6}\right)$ & 96 & $5,701(1,635)$ & 6,022 & $5,380(1,559)$ & 0.046 \\
\hline hemoglobin (g/dL) & 100 & $14.9(1.4)$ & 6,281 & $14.0(1.6)$ & $<0.0001$ \\
\hline platelet count $\left(/ \mathrm{L}^{-10}\right)$ & 77 & $22.6(5.2)$ & 4,512 & $24.1(5.3)$ & 0.012 \\
\hline aspartate aminotransferase (U/L) & 100 & $25.1(10.7)$ & 6,281 & $22.9(13.2)$ & 0.10 \\
\hline alanine aminotransferase (U/L) & 100 & $25.8(18.7)$ & 6,281 & $23.3(16.3)$ & 0.12 \\
\hline proteinuria $(\%)$ & 100 & 6.0 & 6,280 & 4.0 & 0.32 \\
\hline estimated GFR $\left(\mathrm{mL} / \mathrm{min} / 1.73 \mathrm{~m}^{2}\right)$ & 69 & $78.0(12.7)$ & 3,963 & $78.6(13.3)$ & 0.69 \\
\hline vital capacity $(\%)$ & 76 & $93.9(12.2)$ & 4,326 & $96.4(11.5)$ & 0.061 \\
\hline FEV1/FVC (\%) & 76 & $79.4(6.5)$ & 4,327 & $81.1(6.1)$ & 0.021 \\
\hline
\end{tabular}

without. The means of laboratory data and the prevalence of male sex, current smoking, a history of CHD, a history of stroke, and use of antihypertensive, antihypercholes- terolemic, and antidiabetic medication stratified by RBBB are presented in Table 2 . Among the total of 6,381 subjects, 100 subjects had RBBB. Some subjects lacked some labora- 
Table 3. Odds Ratios* of Atrial Fibrillation (AF) and Right Bundle Branch Block $(\mathrm{RBBB})$ in 3,996 Subjects

\begin{tabular}{cccc}
\hline & odds ratio & $95 \%$ confidence interval & $\mathrm{p}$ \\
\hline & atrial fibrillation & & \\
hemoglobin $(\mathrm{g} / \mathrm{dL})$ & 1.67 & $1.25-2.25$ & 0.0006 \\
age (year) & 1.10 & $1.06-1.14$ & $<0.0001$ \\
coronary heart disease & 8.71 & $3.59-21.13$ & $<0.0001$ \\
stroke & 3.50 & $0.93-13.19$ & 0.065 \\
antihypercholesteroleic medication & 0.20 & $0.05-0.74$ & 0.016 \\
body mass index $\left(\mathrm{kg} / \mathrm{m}^{2}\right)$ & 1.17 & $1.04-1.31$ & 0.0083 \\
leucocyte count $\left(/ \mathrm{L}^{-6}\right)$ & 0.9999 & $0.9994-1.0000$ & 0.039 \\
vita capacity $(\%)$ & 0.96 & $0.93-0.99$ & 0.0059 \\
proteinuria & 4.04 & $1.29-12.70$ & 0.017 \\
systolic blood pressure (mmHg) & 0.98 & $0.96-1.00$ & 0.093 \\
LDL cholesterol (mg/dL) & 0.99 & $0.97-1.00$ & 0.062 \\
hemoglobin $(\mathrm{g} / \mathrm{dL})$ & 1.58 & & $<0.0001$ \\
age (year) & 1.04 & $1.31-1.91$ & 0.0017 \\
right bundle branch block & 2.33 & $1.02-1.07$ & 0.0054 \\
antihypercholesterolemic medication & 1.00 & $0.99-1.00$ & 0.062 \\
\hline
\end{tabular}

* with a stepwise logistic regression using AF or RBBB as a dependent variable and sex, age, body mass index, systolic blood pressure, HDL cholesterol, LDL cholesterol, triglycerides, fasting glucose, hemoglobin A1c, leucocyte count, hemoglobin, platelet count, liver function tests, proteinuria, estimated glomerular filtration rate, \% vital capacity, forced expiratory volume in $1 \mathrm{sec}$ over forced vital capacity, smoking status, antihypertensive medication, antidiabetic medication, antihypercholesterolemic medication, history of stroke, and history of coronary heart disease as covariates in 3,996 subjects who had all the above data using exclusion criteria of $\mathrm{p}>0.1$ in stepwise regression

Table 4. Odds Ratios* of Atrial Fibrillation (AF) and Right Bundle Branch Block (RBBB) in 6,379 Subjects

\begin{tabular}{cccc}
\hline & odds ratio & $95 \%$ confidence interval & $\mathrm{p}$ \\
\hline & atrial fibrillation & & \\
hemoglobin $(\mathrm{g} / \mathrm{dL})$ & 1.62 & $1.28-2.05$ & $<0.0001$ \\
age $($ year) & 1.12 & $1.09-1.16$ & $<0.0001$ \\
coronary heart disease & 13.78 & $6.85-27.72$ & $<0.0001$ \\
antihypercholesteroleic medication & 0.22 & $0.08-0.62$ & 0.0041 \\
body mass index $\left(\mathrm{kg} / \mathrm{m}^{2}\right)$ & 1.15 & $1.04-1.27$ & 0.0052 \\
systolic blood pressure $(\mathrm{mmHg})$ & 0.98 & $0.96-1.00$ & 0.083 \\
& 1.53 & & $<0.0001$ \\
hemoglobin $(\mathrm{g} / \mathrm{dL})$ & 1.05 & $1.32-1.77$ & $<0.0001$ \\
age $($ year) & 2.43 & $1.03-1.07$ & 0.012 \\
\hline
\end{tabular}

*with a stepwise logistic regression using $\mathrm{AF}$ or RBBB as a dependent variable and sex, age, body mass index, systolic blood pressure, hemoglobin, smoking status, antihypertensive medication, antidiabetic medication, antihypercholesterolemic medication, history of stroke, and history of coronary heart disease as covariates in 6,379 subjects who had all the above data using exclusion criteria of $p>0.1$ in stepwise regression

tory data. The means of age, BMI, SBP, DBP, fasting glucose, HbA1c, hemoglobin, and leukocyte count and the prevalence of male sex, a history of CHD, use of antihypercholesterolemic medication, and use of antidiabetic medication were significantly higher in subjects with RBBB than in those without. The mean platelet count and FEV1/FVC were significantly lower in subjects with RBBB than those without.

The final results of the stepwise multivariable logistic regression analyses of 3,996 subjects are presented in Table 3. The odds ratio (OR) (95\% confidence interval (CI)) of $\mathrm{AF}$ was $1.67(1.25-2.25) \mathrm{p}=0.0006$ for each $1 \mathrm{~g} / \mathrm{dL}$ increment of hemoglobin, $1.10(1.06-1.14) \mathrm{p}<0.0001$ for each 1 year increment of age, $8.71(3.59-21.13) \mathrm{p}<0.0001$ for a history of
CHD, $0.96(0.93-0.99) \mathrm{p}=0.0059$ for each $1 \%$ increase in the $\% \mathrm{VC}, 1.17(1.04-1.31) \mathrm{p}=0.0083$ for each $1 \mathrm{~kg} / \mathrm{m}^{2}$ increase in BMI, $0.20(0.05-0.74) \mathrm{p}=0.016$ for the use of antihypercholesterolemic medication, $4.04(1.29-12.70) \mathrm{p}=0.017$ for proteinuria, and 0.9999 (0.9994-1.0000) $\mathrm{p}=0.039$ for each 1 count $/ \mathrm{L}^{-6}$ increase in the leukocyte count. The OR (95\% CI) of RBBB was $1.58(1.31-1.91) \mathrm{p}<0.0001$ for each $1 \mathrm{~g} / \mathrm{dL}$ increment of hemoglobin, 1.04 (1.02-1.07) $\mathrm{p}=0.0017$ for each 1 year increment of age, and 2.33 (1.28-4.21) $\mathrm{p}=$ 0.0054 for the use of antihypercholesterolemic medication.

The final results of the stepwise multivariable logistic regression analysis in 6,379 subjects are presented in Table 4. The OR (95\% CI) of AF was $1.62(1.28-2.05) \mathrm{p}<0.0001$ for each $1 \mathrm{~g} / \mathrm{dL}$ increment of hemoglobin, 1.12 (1.09-1.16) $\mathrm{p}<$ 
Table 5. Odds Ratios* of Atrial Fibrillation (AF) by Hemoglobin Tertiles

\begin{tabular}{|c|c|c|c|}
\hline & $\mathrm{T} 1$ & $\mathrm{~T} 2$ & T3 \\
\hline hemoglobin (g/dL) & $6.0-13.4$ & $13.5-14.7$ & $14.8-19.9$ \\
\hline $\mathrm{n}$ & 2,184 & 2,010 & 2,187 \\
\hline prevalence of AF (\%) & 0.37 & 0.60 & 1.9 \\
\hline $\mathrm{p}$ compared with $\mathrm{T} 1$ & & 0.28 & $<0.0001$ \\
\hline odds ratio ${ }^{*}$ of $\mathrm{AF}$ & 1 & 1.07 & 4.32 \\
\hline $95 \%$ confidence interval & & $0.36-3.21$ & $1.29-14.43$ \\
\hline p compared with T1 & & 0.90 & 0.017 \\
\hline
\end{tabular}

0.0001 for each 1 year increment of age, 13.78 (6.85-27.72) $\mathrm{p}<0.0001$ for a history of CHD, $0.22(0.08-0.62) \mathrm{p}=0.0041$ for the use of antihypercholesterolemic medication, and 1.15 (1.04-1.27) $\mathrm{p}=0.0052$ for each $1 \mathrm{~kg} / \mathrm{m}^{2}$ increase in the BMI. The OR (95\% CI) of RBBB was $1.53(1.32-1.77) \mathrm{p}<0.0001$ for each $1 \mathrm{~g} / \mathrm{dL}$ increment of hemoglobin, 1.05 (1.03-1.07) $\mathrm{p}<0.0001$ for each 1 year increment of age, and 2.43 (1.224.87) $\mathrm{p}=0.012$ for a history of CHD.

The OR (95\% CI) of AF for each upper tertile of hemoglobin compared with the first tertile are shown in Table 5 and Fig. 1. The OR $(95 \% \mathrm{CI})$ of AF was 1.07 (0.36-3.21) $\mathrm{p}=0.90$ and $4.32(1.29-14.43) \mathrm{p}=0.017$, respectively for the second the third tertiles of hemoglobin. The OR $(95 \% \mathrm{CI})$ of RBBB for each upper quartile of hemoglobin compared with the first quartile are shown in Table 6 and Fig. 2. The OR $(95 \% \mathrm{CI})$ of RBBB was $2.53(1.06-6.00) \mathrm{p}=0.036,3.10$ $(1.12-8.61) \mathrm{p}=0.030$, and $4.03(0.91-17.82) \mathrm{p}=0.066$, respectively for the second, the third, and the forth quartiles of hemoglobin.

\section{Discussion}

In the present study, we demonstrated that increased blood levels of hemoglobin were independently associated with $\mathrm{AF}$ and RBBB after adjusting for sex, age, and other confounding covariates in apparently healthy subjects. To the best of our knowledge, there has been no study showing an independent association between increased hemoglobin levels and AF or RBBB.

In the univariate analysis, male sex, age, BMI, SBP, DBP, HDL cholesterol, triglycerides, fasting glucose, HbAlc, hemoglobin, the leukocyte count, proteinuria, \%VC, FEV1/ FVC, and a history of CHD were significantly associated with AF or RBBB. These associations suggest that there is association of $\mathrm{AF}$ and $\mathrm{RBBB}$ with metabolic syndrome (11), CHD, diabetes, chronic kidney disease, and chronic lung disease. However, the independent associations of $\mathrm{AF}$ and RBBB with increased hemoglobin levels are not sufficiently explained by these contexts. In patients with a failing heart, AF or RBBB leads to deleterious effects on the hemodynamics, although neither of them is usually associated with overt compromising effects on the hemodynamics in subjects with a normal heart if the heart rate is controlled in the

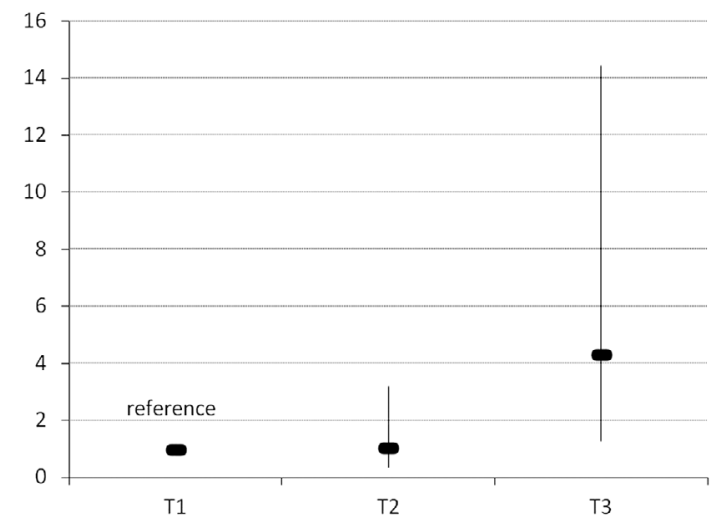

Figure 1. The odds ratios ( $95 \%$ confidence interval) of $\mathbf{A F}$ for the second (T2) and the third (T3) tertiles of hemoglobin compared with the first tertile (T1) adjusted for sex, age, smoking status, use of antihypertensive medication, antidiabetic medication, antihypercholesterolemic medication, and histories of stroke and coronary heart disease (see Table 5 for the numerical data).

case of AF. However, even in subjects with a normal heart, there may be some subclinical hemodynamic effects of $\mathrm{AF}$ or RBBB on the systemic organs, because ventricular pump performance may be adversely affected by the lack of atrial kick in $\mathrm{AF}$ and the asynchronous contraction of the ventricles in cases of RBBB. A possible effect of subclinical tissue hypoperfusion on systemic organs may be a hypoxic stimulus, which increases the synthesis and release of erythropoietin (EPO) $(12,13)$. Erbayraktar et al. reviewed the evidence that EPO and its receptor function as a paracrine/autocrine system to mediate the protection of tissues subjected to metabolic stress (14). Thus, a possible explanation for the associations between AF or RBBB and the increased levels of hemoglobin is that increased blood levels of hemoglobin may reflect increased erythropoiesis which results from subclinical tissue hypoperfusion caused by $\mathrm{AF}$ or RBBB in an apparently normal heart. In contrast, patients with chronic heart failure are frequently anemic despite elevated endogenous EPO levels due to EPO resistance which results from impaired EPO-induced signal transduction (15) and a suppression of erythropoiesis by heart failure-related inflammation (16). EPO induces positive inotropic and lusitropic effects in the murine and human myocardium (17). The increased blood levels of EPO and hemoglobin with an intact EPO signaling cascade may compensate for the subclinical adverse hemodynamic effects of AF or RBBB and prevent the development of overt heart failure together with other compensatory mechanisms such as the reninangiotensin-aldosterone system and autonomic nervous system in apparently normal heart.

Another explanation for the associations between AF or RBBB and hemoglobin is that hypoxia of unknown origin may simultaneously stimulate erythropoiesis and depress the conductivity of the heart $(18,19)$ and ultimately bring about AF or RBBB. Hypoxia may results from chronic lung dis- 
Table 6. Odds Ratios* of Complete Right Bundle Branch Block (RBBB) by Hemoglobin Quartiles

\begin{tabular}{ccccc}
\hline & $\mathrm{Q} 1$ & $\mathrm{Q} 2$ & $\mathrm{Q} 3$ & $\mathrm{Q} 4$ \\
\hline hemoglobin $(\mathrm{g} / \mathrm{dL})$ & $6.0-13.0$ & $13.1-14.1$ & $14.2-15.1$ & $15.1-19.1$ \\
$\mathrm{n}$ & 1,618 & 1,638 & 1,581 & 1,544 \\
prevalence of RBBB (\%) & 0.5 & 1.3 & 1.9 & 2.6 \\
p compared with Q1 & & 0.017 & 0.0003 & $<0.0001$ \\
odds ratio ${ }^{*}$ of RBBB & 1 & 2.53 & 3.10 & 4.03 \\
95\% confidence interval & & $1.06-6.00$ & $1.12-8.61$ & $0.91-17.82$ \\
p compared with Q1 & & 0.036 & 0.030 & 0.066 \\
\hline
\end{tabular}

adjusted for sex, age, smoking status, antihypertensive medication, antidiabetic medication, antihypercholesterolemic medication, history of stroke, and history of coronary heart disease

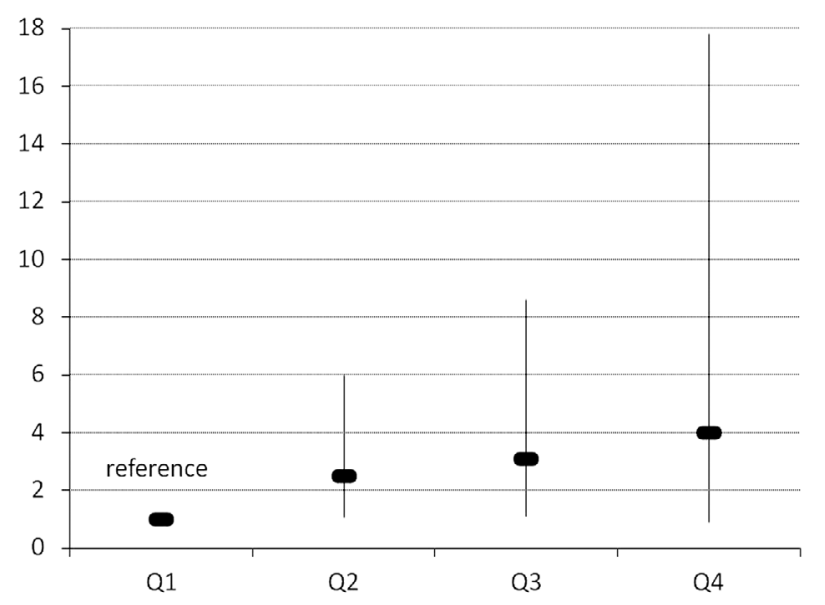

Figure 2. The odds ratios ( $95 \%$ confidence interval) of RBBB for each upper quartile (Q2-Q4) of hemoglobin compared with the first quartile (Q1) adjusted for sex, age, smoking status, use of antihypertensive medication, antidiabetic medication, antihypercholesterolemic medication, and histories of stroke and coronary heart disease (see Table 6 for the numerical data).

ease, which may predispose to $\mathrm{AF}$ or $\mathrm{RBBB}$ as a result of pulmonary hypertension. However, in the present study, the age- and sex-adjusted partial correlation coefficients between hemoglobin and the \%VC or FEV1/FVC were 0.0091 ( $\mathrm{p}=$ $0.55)$ and $-0.022(\mathrm{p}=0.15)$, respectively, which indicates that there are no significant associations between hemoglobin and the respiratory function, although we did not measure the pulmonary arterial pressure. Alternatively, there may be some unknown molecular cross-talks between erythropoiesis and the conductivity of the heart (20). Furthermore, it may be possible that erythropoiesis is a cause of AF and RBBB, not a result. Elevated hemoglobin levels causing high blood viscosity might increase the cardiac work load and subsequent right ventricular expansion and left atrial dilatation leading to RBBB and AF.

Although the exact mechanisms are unknown, the present study provides the first evidence that there are independent associations between $\mathrm{AF}$ and $\mathrm{RBBB}$ and increased blood levels of hemoglobin in apparently healthy subjects. Electrocardiography should therefore be recommended for asymptomatic subjects found to have increased hemoglobin levels during health screening examinations.

The present study was a cross-sectional study and the number of subjects was relatively small. Thus, the causeeffect relationships between $\mathrm{AF}$ or RBBB and the hemoglobin levels were not known, and the conclusion was hypothetical. The above discussion was based on speculation, because the EPO levels, blood oxygen concentrations, tissue perfusion data, and other relevant tests regarding the mechanisms underlying the association were not performed in the present study. Future studies are required to elucidate the cause-effect relationship and the mechanisms underlying the association between AF or RBBB and the hemoglobin levels in apparently healthy subjects.

The authors state that they have no Conflict of Interest (COI).

\section{Acknowledgement}

We thank all subjects who participated in the study, and the paramedical staff at our center who assisted with the study.

We received no grants to support this study, and have no conflict of interest to declare.

\section{References}

1. Estes NAM III, Halperin JL, Calkins H, et al. ACC/AHA/Physician Consortium Performance Measures. ACC/AHA/Physician Consortium 2008 clinical performance measures for adults with nonvalvular atrial fibrillation or atrial flutter: a report of the American College of Cardiology/American Heart Association Task Force on Performance Measures and the Physician Consortium for Performance Improvement (Writing Committee to Develop Clinical Performance Measures for Atrial Fibrillation). Circulation 117: 1101-1120, 2008.

2. Fuster V, Rydén LE, Asinger RW, et al. ACC/AHA/ESC guidelines for the management of patients with atrial fibrillation: executive summary: a report of the American College of Cardiology/ American Heart Association Task Force on Practice Guidelines and the European Society of Cardiology Committee for Practice Guidelines and Policy Conferences (Committee to Develop Guidelines for the Management of Patients With Atrial Fibrillation): developed in collaboration with the North American Society of Pacing and Electrophysiology. J Am Coll Cardiol 38: 1231-1266, 2001.

3. Fuster V, Rydén LE, Cannom DS, et al. ACC/AHA/ESC 2006 guidelines for the management of patients with atrial fibrillation: executive summary: a report of the American College of Cardiol- 
ogy/American Heart Association Task Force on Practice Guidelines and the European Society of Cardiology Committee for Practice Guidelines and Policy Conferences (Writing Committee to Revise the 2001 Guidelines for the Management of Patients With Atrial Fibrillation). J Am Coll Cardiol 48: 854-906, 2006.

4. De Bacquer D, De Backer G, Kornitzer M. Prevalences of ECG findings in large population based samples of men and women. Heart 84: 625-633, 2000.

5. Rotman M, Triebwasser JH. A clinical and follow-up study of right and left bundle branch block. Circulation 51: 477-484, 1975.

6. Pine MB, Oren M, Ciafone R, et al. Excess mortality and morbidity associated with right bundle branch and left anterior fascicular block. J Am Coll Cardiol 1: 1207-1212, 1983.

7. McNamara RL, Brass LM, Drozda JP Jr, et al. ACC/AHA key data elements and definitions for measuring the clinical management and outcomes of patients with atrial fibrillation: a report of the American College of Cardiology/American Heart Association Task Force on Clinical Data Standards (Writing Committee to Develop Data Standards on Atrial Fibrillation). Circulation 109: 3223-3243, 2004.

8. Siegman-Igra Y, Yahini JH, Goldbourt U, Neufeld HN. Intraventricular conduction disturbances: a review of prevalence, etiology, and progression for ten years within a stable population of Israeli adult males. Am Heart J 96: 669-679, 1978.

9. Warnick GR, Knopp RH, Fitzpatrick V, Branson L. Estimating low-density lipoprotein cholesterol by the Friedewald equation is adequate for classifying patients on the basis of nationally recommended cutpoints. Clin Chem 36: 15-19, 1990.

10. Matsuo S, Imai E, Horio M, et al. Revised equations for estimated GFR from serum creatinine in Japan. Am J Kidney Dis 53: 982992, 2009.
11. Oda E. (2012) Metabolic syndrome: its history, mechanisms, and limitations. Acta Diabetol 49: 89-95, 2012.

12. Frede S, Freitag P, Geuting L, Konietzny R, Fandrey J. Oxygenregulated expression of the erythropoietin gene in the human renal cell line REPC. Blood 117: 4905-4914, 2011.

13. Yoon D, Ponka P, Prchal JT. Hypoxia. 5. Hypoxia and hematopoiesis. Am J Physiol Cell Physiol 300: C1215-C1222, 2011.

14. Erbayraktar S, Yilmaz O, Gökmen N, Brines M. Erythropoietin is a multifunctional tissue-protective cytokine. Curr Hematol Rep 2: 465-470, 2003.

15. Okonko DO, Marley SB, Anker SD, Poole-Wilson PA, Gordon MY. Erythropoietin resistance contributes to anaemia in chronic heart failure and relates to aberrant JAK-STAT signal transduction. Int J Cardiol 2011 Aug 5 [Epub ahead of print].

16. Okonko DO, Marley SB, Anker SD, Poole-Wilson PA, Gordon MY. Suppression of erythropoiesis in patients with chronic heart failure and anaemia of unknown origin: evidence of an immune basis. Int J Cardiol 2011 Dec 20 [Epub ahead of print].

17. Hefer D, Yi T, Selby DE, et al. Erythropoietin induces positive inotropic and lusitropic effects in murine and human myocardium. J Mol Cell Cardiol 52: 256-263, 2012.

18. Bagdonas AA, Stuckey JH, Piera J, Amer NS, Hoffman BF. Effects of ischemia and hypoxia on the specialized conducting system of the canine heart. Am Heart J 61: 206-218, 1961.

19. Streit J. Effects of hypoxia and glycolytic inhibition on electrical properties of sheep cardiac Purkinje fibres. J Mol Cell Cardiol 19: 875-885, 1987.

20. Anderson ER, Xue X, Shah YM. Intestinal hypoxia-inducible factor- $2 \alpha$ (HIF-2 $\alpha)$ is critical for efficient erythropoiesis. J Biol Chem 286: 19533-19540, 2011.

(C) 2013 The Japanese Society of Internal Medicine http://www.naika.or.jp/imonline/index.html 